\title{
FAZER CULTURA. FAZER(-SE) ESTADO. VERNISSAGES E PERFORMATIVIDADE DE ESTADO EM CÓRDOBA
}

Gustavo Blázquez

\begin{abstract}
El poder también se sostiene en la ficción
El Estado es también una máquina de hacer creer.

Ricardo Piglia, Crítica y ficciones, 1986.
\end{abstract}

\section{Fazer(-se) Estado}

Como assinalam Bourdieu (1994) e Taussig (1992), entre outros, entregarse à tarefa de pensar analiticamente o Estado é expor-se ao perigo de sucumbir a seu encantamento. O brilho, fálico talvez, seu caráter de fetiche e seu " $E$ " maiúsculo têm o poder mágico de fazer com que nos percamos entre suas representações e em seus efeitos encantados e encantadores. Enquanto trabalhadores do Estado, empregados públicos da Ciência e do Saber universitário, também corremos o risco de encantar nossas próprias crenças sobre as formas de organização estatal com os discursos doutos que produzimos, mantendo-as intactas e fora de qualquer crítica. Conscientes destes perigos e com a pretensão talvez também mágica de dar conta do Estado, buscaremos, com o auxílio da Antropologia, desnaturalizar um certo "senso comum intelectual".

Este senso comum, como mostram Souza Lima e Castro (2008), entende as políticas culturais como um plano de ação para guiar decisões e ações e, como consequência, dedica-se à análise das condições de emergência, mecanismos de operação e prováveis impactos dos programas governamentais sobre a ordem social e econômica. Nessas análises, as ações das políticas públicas são representadas então como o resultado da capacidade do Estado-nação (liberal-democrático) de resolver problemas públicos. Estes estudos sustentam uma visão racionalista e instrumental do Estado e tentam compreender suas ações do ponto de vista da eficácia de suas práticas. As políticas públicas aparecem então como o resultado da identificação de 
um "problema social" que levaria à formulação de argumentos racionais que o expliquem e dos quais se desprenderia um conjunto de respostas e planos de ação para sua resolução (Cf. Lenoir 1993). A aplicação destes, por parte de técnicos e especialistas, e sua avaliação final, completariam um círculo encantado em que se destaca a (in)capacidade de ação do Estado para oferecer respostas às demandas sociais.

Entretanto, as políticas governamentais poderiam ser entendidas como planos, ações, saberes e tecnologias de governo através das quais determinados agentes produziriam, como parte de um processo social flexível, contraditório, conflitivo, cambiante e sempre em movimento, Estado. Mais do que com um "Estado", elevado à categoria de um agente do processo social capaz de desenvolver políticas, nós nos depararíamos antes com práticas e discursos que produzem o Estado performativamente quando o citam, seguidamente, como o agente racional e eficaz que ele se diz ser.

Uma estratégia possível para acercarmo-nos do Estado tentando não sucumbir a seu brilho seria embrenharmo-nos em suas vielas traçando uma etnografia de como "funciona" o "dispositivo" (Foucault 1975), com o objetivo de desmontá-lo e descrevê-lo em sua atuação específica. Essas aproximações partem do questionamento das definições programáticas das políticas governamentais e abandonam a crença, um tanto paranoica, na existência de um Estado. Ao transformar o "E" maiúsculo em séries de práticas de governo de populações, conformadas por conjuntos de decisões e atos de vontade mais ou menos sistemáticos de determinados sujeitos sociais sobre o uso de instrumentos, regras, estratégias e objetivos que regulam diferentes práticas sociais, torna-se possível lidar com a força constitutiva do Estado capaz de criar-se e de criar as realidades que enuncia. Políticas indigenistas, educativas, sanitárias, para imigrantes, "menores" ou "juventude", entre outras, resultam, quando observadas a partir de obscuros corredores e vielas administrativas, em agregados heterogêneos de ações de gestão por parte de estruturas estatizadas de intervenção cotidiana na vida social de determinadas populações no interior de um território específico (Cf. Castro 2009; Corrêa 2002; Pacheco de Oliveira 1988; Souza Lima 1995, 2002; Lugones 2009; Ramos 2002; Vianna 2002).

Neste trabalho nos propomos a desenvolver outra estratégia analítica: acercarmo-nos do "Estado" em seus momentos de brilho e esplendor. Como nos ensinou Clifford Geertz em sua análise do Negara, a pompa não é um puro ornamento, mas uma dimensão constitutiva do Estado balinês que resplandece nas performances que o colocam em cena (Cf. Geertz 1981). Interessa-nos observar isso a que se chama Estado quando ele tem que representar a si mesmo e dar-se a conhecer através de modos altamente 
estetizados qua apelam para a captação sensorial e envolvem os sujeitos a partir da estimulação poética de seu sensório. Interessa-nos vê-lo quando se faz fazer, quando se faz representar e, tal como uma esfinge, se faz elevar como uma realidade objetiva ainda que fantasmagórica. ${ }^{1}$ Que ideias de Estado o Estado produz em suas performances?

Tratando, como quixotes contemporâneos, de distinguir gigantes de moinhos de vento, buscaremos o Estado em suas performances espetaculares. Ao invés de mergulhar nas intervenções surdas na vida cotidiana, procuramos encontrar o "Estado" na iridescência magnífica de suas encenações. Entendemos por "perfomance de Estado" atos ou cerimônias organizadas por corpos administrativos estatizados que encenam o "Estado" como um agente definido do processo social. São atos de "atos de Estado". Exercícios repetitivos, "condutas restauradas" (Schechner 2000), nunca originais e sempre realizadas pela segunda vez, nos quais o "Estado" se encontra com e se dá a encontrar pelos concidadãos.

Em outros trabalhos (Cf. Blázquez 1998) discuti como o Estado argentino se apresenta enquanto Estado-nação e, mais especificamente, como Pátria, através de um conjunto de cerimônias escolares realizadas por ocasião das efemérides nacionais chamadas atos escolares. Estas performances de Estado, ao mesmo tempo em que recordam acontecimentos históricos e sancionam valores cívicos considerados fundantes da argentinidade, permitem a instituição de hierarquias e desigualdades. Geradas no final do século XIX e ainda presentes na educação nacional, as performances patrióticas escolares fazem parte do sempre inconcluso processo de instauração do Estado. Em torno delas - e, de um modo geral, em torno da educação que as contém e desenvolve - constituiu-se um corpo de funcionários governamentais e especialistas cuja reprodução social dependia e depende desta participação na administração estatal. Em torno dos atos escolares se constitui e funde uma memória nacional com as recordações da infância, ao mesmo tempo em que eles oferecem a possibilidade de exibir ostentosamente capitais culturais, corporais, econômicos e sociais acumulados pelos grupos familiares.

Dando continuidade a essas investigações, o presente trabalho se concentra em "performances de Estado" nas quais a "Cultura" aparece como um recurso (Yúdice 2002). Inaugurações de museus e centros culturais, criação de corredores culturais, construção de monumentos, organização de prêmios e salões, concertos, ciclos de cinema, festivais, vernissages, entregas de distinções honoríficas e pensões vitalícias são algumas destas "performances de Cultura" cada vez mais frequentes nos marcos do chamado "capitalismo cultural" (Rifkin 2002). 


\section{A cultura como recurso: "Cultura para todos"}

Aos sentidos que o termo "cultura" concentrou até a década de 1970, incorporou-se um significado novo associado às transformações do capitalismo cultural (Rifkin 2000; Yúdice 2002; Žižek 2003). De acodo com a análise de George Yúdice, a cultura na atualidade constitui uma base legitimadora a partir da qual é possível um melhoramento das condições sociais, econômicas e políticas. A nova estratégia de legitimação da cultura baseia-se na sua utilidade para a resolução de problemas sociais, assim como para estimular o crescimento econômico. A cultura enquanto recurso alcançaria apenas o âmbito do crescimento econômico. A cultura constituiria também uma fonte para a construção e o fortalecimento da cidadania local. A cultura seria também um recurso para a desarticulação de identidades essencializadas, a-históricas e não conflitivas, às quais os sujeitos deveriam ser forçosamente associados e, deste modo, para a emergência de novas subjetividades (Yúdice 2002). Para Rifkin, além de terem transformado a Natureza em bens de propriedade, as sociedades ocidentais transformaram as experiências culturais em recursos negociáveis em um mercado ligado ao entretenimento, à privatização e à mercantilização dos bens culturais.

A cultura - nossa experiência compartilhada — está se convertendo em um objeto econômico graças ao poder que as novas tecnologias da comunicação começaram a exercer em nossa vida cotidiana. [...] Assegurar o acesso às próprias experiências de vida tornou-se tão importante quanto o foi ser proprietário na era dominada pela produção de bens industriais (Rifkin 2000:188).

A estruturação da vida social baseia-se cada vez mais na possibilidade de ter acesso simbólico aos bens culturais, mais do que em ter sua propriedade. No caso de sua apropriação material, como destaca Benjamin (1989), a mesma se realizaria na forma de uma cópia, possibilitada pelas novas tecnologias da reprodução mecânica. A reprodução técnica da imagem e do som associada à formação das massas modificaria tanto a função da obra de arte como o aparato sensorial expressos na experiência de trituração da aura (Benjamin 1989). Estas transformações encontravam-se esgarçadas na formação de um mercado de bens culturais que, ainda que públicos, se produziriam e mercantilizariam em mãos do capital privado. O rádio, o cinema, a televisão, mas também o turismo, o entretenimento, a moda, a cozinha, as artes plásticas e o artesanato, o teatro e a pornografia constituiriam então uma espécie de "vanguarda comercial da era do acesso" (Rifkin 2000:189). Em torno de todo um conjunto de práticas "culturais" se formaria o lócus 
da mutação de um capitalismo industrial baseado na produção de bens em um capitalismo cultural interessado na produção de serviços e no crescente desenvolvimento da "indústria cultural".

A ênfase no (direito ao) acesso, própria do capitalismo cultural, pode ser observada no slogan publicitário da Secretaria de Cultura da Província de Córdoba para o período 2007-2011: "Cultura para todos em todos os lugares". Este enunciado era uma reelaboração tanto do slogan do Poder Executivo provincial, "Córdoba entre todos", quanto da agência estatal de administração da Cultura do governo anterior do mesmo partido. ${ }^{2} \mathrm{O}$ slogan oficial, presente em uma infinidade de espaços, desde os grandes cartazes publicitários até os pequenos convites para uma inauguração, acentuava a ideia da facilitação do acesso à "Cultura" a partir de sua disseminação generalizada como uma tarefa de "Estado". ${ }^{3}$

Não se tratava apenas de continuar protegendo os "bens culturais", tarefa prescrita pela Lei Provincial n. 5543, sancionada em abril de 1973 por um governo de fato, e seu Decreto Regulamentador 484/83, de fevereiro de 1983, da última ditadura militar. A "Cultura", reconhecida agora como um direito universal, era uma necessidade a que o Estado da Província de Córdoba da última década se propunha e efetivamente dizia atender.

Para facilitar o acesso à "Cultura", um termo que parecia não precisar de definição, e como uma aposta na "valorização do patrimônio cultural local", foi posta em marcha uma série de ações destinadas a assegurar "Cultura para todos em todos os lugares". Uma das primeiras ações foi a recuperação do "legado" jesuítico da província e as negociações que permitiram declará-lo "Patrimônio da Humanidade" pela Assembleia Anual da UNESCO, em 2000. ${ }^{4}$

Talvez a mais visível dessas ações tenha sido a criação da chamada "Meia légua de ouro cultural", um corredor cultural que atravessa uma área central da cidade de Córdoba. Segundo a descrição do site da Secretaria de Cultura: ${ }^{5}$

A Meia Légua de Ouro Cultural é um trajeto que abarca cerca de 2.500 metros entre a histórica Plaza San Martín e o discreto bairro de Nueva Córdoba, descansando sobre o majestoso Parque Sarmiento projetado há mais de um século pelo arquiteto Charles Tahys.

Ali se encontram os centros destinados à produção cultural mais importantes da Província, caracterizando um distrito cultural de grande diversidade e elegância, ao estilo das grandes capitais do mundo. Um circuito que recupera para todos os cordobeses e aqueles que nos visitam um conglomerado de espaços culturais de grande valor quanto a seu patrimônio arquitetônico e artístico (http://www.cba.gov.ar/vercanal.jsp?idCanal=59181). 
Esse trajeto, cujo nome se refere a uma unidade de medida colonial fora de uso na linguagem cotidiana atual, inicia-se em um teatro oficial remodelado, o Teatro Real, reinaugurado em 2007, e culmina no polo artístico mais importante da América Latina: a Cidade das Artes. Este conjunto arquitetônico municipal aberto em 2005 pertencia antigamente ao Exército e nele se concentraram, a partir de 2005, todas as instituições educativas provinciais relacionadas às artes.

O circuito dourado inclui em seu trajeto o tradicional Teatro Libertador San Martín, concebido segundo as tendências dos teatros líricos europeus; o passeio do Buen Pastor, com um ambiente de águas dançantes, galerias de arte, capela restaurada aberta ao público, restaurantes e lojas comerciais, inaugurado em 2004, localizado no que fora a prisão de mulheres e um convento; um museu de Ciências Naturais que se abre como espiral para viajar até as origens do universo, e dois Museus de Belas Artes: o Museu Superior de Belas Artes Evita - Palácio Ferreyra, que abriga a centenária coleção provincial de artes plásticas, e o Museu Provincial de Belas Artes Emilio Caraffa, um cenário privilegiado da arte contemporânea. ${ }^{6}$

Os festejos do Bicentenário da Revolução de Maio resultaram em uma proveitosa oportunidade para continuar essas transformações do espaço público. Por exemplo, incorporaram-se a este corredor cultural o Passeio do Bicentenário, ${ }^{7}$ o monumento a um militar cordobês do século XIX, ${ }^{8}$ e o Farol do Bicentenário. ${ }^{9}$ Também se demoliu a sede do Poder Executivo local, localizada na mesma zona geográfica, e em seu lugar foi construído um passeio público que abrigará um observatório astronômico.

Recuperar um determinado "patrimônio cultural" fortemente marcado pelo viés colonial e colocá-lo à disposição de "todos" era um anseio, uma obrigação, um slogan e uma prática governamental. Diante de nossos olhos, entre ruínas das quais surgiam novos museus, passeios culturais, bares, centros de compras e parques, a "Cultura para todos" tornava-se um recurso na reprodução do "Estado". Nesta tarefa não participou apenas o Estado provincial. A Universidade Nacional de Córdoba, com a ampliação do Museu de Antropologia localizado na "Meia légua de ouro cultural", e a Igreja Católica, com a restauração de vários templos coloniais, também se integraram nesse processo de fazer "Cultura para todos". ${ }^{10}$

\section{Performances no capitalismo cultural}

A transformação da cultura em um recurso, associada ao capitalismo cultural, à prática do turismo de massa e à mercantilização das experiências, 
demandaria e se realizaria em uma série de performances específicas, como os vernissages que analisaremos mais adiante. A teatralização e a invisibilização dos processos de produção fazem parte das estratégias básicas do capitalismo tardio, já que não consumimos apenas objetos materiais mas também, e fundamentalmente, "estilos de vida" e "culturas". As vivências, como colocou a Internacional Situacionista, ${ }^{11}$ tornaram-se mercadoria sob a lógica da "Sociedade do Espetáculo", na qual "tudo o que é diretamente experimentado se converteu em uma representação" (Debord 1999a:37).

O espetáculo, segundo as propostas do filósofo e cineasta Guy Debord, não deve ser entendido como um engano, uma falsa realidade, um suplemento do mundo real ou um adorno de última hora, pelo contrário, "se trata antes de uma Weltanschauung que se tornou efetiva, que se traduziu em termos materiais" (Debord 1999a:38). ${ }^{12}$ Na era do espetáculo e do capitalismo cultural, não só as peformances ocupam a cena, como também o próprio vocábulo "performance" se tornou massivo. ${ }^{13}$ Essa disseminação do termo e das práticas designadas com este nome de origem latina, mas não reconhecido pelo Dicionário da Língua Espanhola da Real Academia Espanhola, nos permite imaginar a emergência de uma "sociedade da performance" como parte do desenvolvimento capitalista contemporâneo.

Para descrever esta sociedade, utilizamos o termo performance em um duplo sentido. Em primeiro lugar, entendemos com ele as práticas artísticas vanguardistas que utilizam principalmente recursos dramáticos. Esta forma da arte contemporânea, empenhada em representar o ideal lacaniano (Phelam 1993), é "essencialmente o movimento (de corpos e de processos de significação) que impulsiona o espetáculo ou o evento" (Angerer 2009:180) mais do que a encenação de um texto prévio. Em segundo lugar, queremos recuperar outro dos sentidos do termo performance. Antes da chegada dos artistas da performance e dos performance studies (Cf. Schechner 2000; Turner 1986), entendia-se por perfomance o rendimento de um bem ou produto. Assim, falava-se, e continua se falando, da alta ou baixa performance de automóveis, de óleos lubrificantes ou das ações no mercado de capitais.

Parafraseando a definição de espetáculo que Debord (1999a) propõe na tese quatro de $A$ sociedade do espetáculo, propomos que "a performance não é um conjunto de ações dramáticas, mas uma relação social entre as pessoas mediatizada pelas representações de ações dramáticas". Nesta imaginária e imaginada "Sociedade da Performance", as relações sociais tornar-se-iam representações dramáticas que citariam e repetiriam uma experiência anterior vazia/esvaziada pela cultura do espetáculo. "Passar" por quem se é, quer dizer, ser reconhecido por quem a pessoa se diz ser a partir de uma "boa" performance de si, faria parte das preocupações exis- 
tenciais dos membros desta sociedade. As performances de si seriam uma dimensão valorizada do eu na qual se investiria tempo, dinheiro e emoções. Se o espetáculo "não diz mais que isto: 'o que aparece é bom e é bom o que aparece'" (Debord 1999a:41), talvez o que a performance afirme seja que "o que aparece rende, o que rende aparece".

Nesta "Sociedade da Peformance" uma maneira frequente de nos encontrarmos com o Estado seria através de suas representações dramáticas que, como adverte Schechner (2000), além de serem, fazerem, mostrarem o fazer e explicarem as ações demonstradas, fazem crer. As performances seriam parte das tecnologias de governo. Neste sentido, as diferentes encenações constituiriam elementos das políticas culturais ou das políticas governamentais de gestão da "Cultura". Recuperando as apostas teóricas de Max Gluckman (1958) — e da chamada "Escola de Manchester" — quanto a seu conceito de "situações sociais", as performances poderiam ser entendidas como realizações efetivas de políticas culturais e, por isto, constituiriam uma via régia para sua análise.

As "performances de Cultura", quer dizer, aquelas em que o "Estado" se mostra sendo e fazendo "Cultura", permitem analisar que políticas governamentais se realizam em nome da "Cultura" e que formas adquire este fazer. Que "Cultura" faz o "Estado"? Quais são as tecnologias de subjetivação e as formas de governamentalidade que se realizam em e através dessas performances? Quais são os estilos de fazer "Estado" que se colocam em cena? Como se faz "Estado" quando se faz "Cultura"? ${ }^{14}$

\section{Os vernissages como performances de Cultura}

Vernissage no campo das Artes Plásticas nomeia uma cerimônia festiva que reúne um conjunto de pessoas para brindar e assim dar por inaugurada uma exposição. ${ }^{15} \mathrm{O}$ vernissage, o "cocktail de abertura", é uma performance que marca a passagem dos dias e meses anteriores, quando se preparavam as obras, para o momento de sua exibição pública.

Primeiro momento de uma exposição, os vernissages são ações altamente significativas e de importante visibilidade. Como indicado por seu sentido em francês, o vernissage dá brilho e lustre mas não somente aos quadros. Sua realização se dá de acordo com uma poética e um script não escrito, mas preestabelecido que supõe, por exemplo, o desfile de bandejas com vinhos e bebidas várias acompanhadas de sanduíches, canapés e todo tipo de comida em miniatura que não requeira o uso de talheres. Dado que o objetivo do vernissage é a socialização, os alimentos não devem ser de tamanho grande para permitir a livre circulação do público. 
Esta performance diz e faz a inauguração de uma mostra de arte, tornando-se parte das "condições de felicidade" que asseguram a performatividade dos enunciados que ali se produzem. A partir desse momento, ou melhor ainda, a partir do dia seguinte, a mostra está aberta e é oferecida ao grande público.

A data e a hora da performance são comunicadas aos convidados com antecedência por meio de convites especiais. Quando se trata de eventos em que os convidados incluem idealmente toda a comunidade - tipo aberto ao público - sua realização é difundida através da imprensa. É comum que os jornais informem a inauguração de exposições, que se realizam sempre em horário vespertino, pouco antes do pôr-do-sol, quando o dia está virando noite. Este horário é expressivamente oposto aos horários de visitação habituais, que culminam antes do entardecer. Esta variação temporal contribui para marcar o caráter excepcional e único do vernissage.

Quem está convidado? Quais são as políticas de convite? O que dizem e fazem estas políticas? Que Estado se faz com e nelas? O que fazem os convidados? Quem e como se fazem convidar? Para responder a algumas destas perguntas, deter-me-ei na análise dos vernissages realizados em um museu de Belas Artes, que foi restaurado, na cidade de Córdoba, o Museu Emilio Caraffa, ou MEC, dos quais participei regularmente entre 2007 e 2011. ${ }^{16}$

O Museu Caraffa, cujas bases foram assentadas em 1914, está localizado na entrada de um grande parque da cidade, antigamente rodeado de residências burguesas hoje demolidas, e onde se erguem edifícios de apartamentos para milhares de estudantes universitários. Em torno deste museu organizou-se grande parte do campo artístico cordobês, e sua posição sempre foi hegemônica, com suas salas outorgando uma consagração significativa aos que nelas expunham. Sua imagem tem uma força considerável no imaginário do campo artístico local, o que leva alguns agentes a sonharem em estar ali e a verem seus nomes escritos nos cartazes que marcam a entrada, ou a desejarem incendiá-lo como se se tratasse de atender a um mandato futurista.

Em 2007, como parte da Meia Légua de Ouro Cultural, o Museu foi reformado e ampliado. Ao mesmo tempo em que se modificou a posição da porta de entrada e se trocou o logotipo institucional, ele deixou de chamarse "o Caraffa" e passou a ser "o MEC". Essas transformações foram acompanhadas de um incremento no número de trabalhadores na instituição a partir de contratos temporários, que incorporaram um conjunto de jovens profissionais, muitos deles com formação no campo das artes plásticas, do jornalismo ou da gestão cultural. Com este pessoal precarizado em termos de direitos trabalhistas e com um importante capital cultural, organizou-se 
toda uma engenharia institucional que se ocupou de colocar o Museu em movimento. As atividades estavam organizadas por áreas como: Administração e RH, Comunicação, Produção, Pesquisa, Educação, Coleção, Desenho Gráfico, Montagem, Biblioteca, Direção, além das que se encarregavam da manutenção, da atenção ao público e da segurança (cf. http://www.museocaraffa.org.ar). Em 27 de dezembro de 2007 inaugurou-se oficialmente o (novo) Museu Provincial de Belas Artes Dr. Emilio Caraffa.

Com um concerto da Orquesta Sinfônica da Província, foram inauguradas esta noite as obras de restauro e remodelação do Museu Provincial Emilio Caraffa, localizado na avenida do Dante. Córdoba tem um novo museu. Não apenas maior, mas também diferente, conservando em uma de suas faces a velha fisionomia e ganhando espaço para completar uma imensa estrutura a que se terá acesso normalmente não pela praça Espanha, mas pela avenida Poeta Lugones. O Caraffa será reaberto com uma estrutura três vezes maior do que a que tinha antes da ampliação de 1962: de três salas passará a contar agora com nove, somando no total mais de sete mil metros quadrados. Para conhecer o museu. A partir de hoje, e depois do concerto, se farão visitas para grupos de até 200 pessoas. Depois, o Museu Caraffa poderá ser visitado de terça a domingo de 10 às 21 horas. A entrada é livre e gratuita. [...]

A exposição selecionada para esta reinauguração histórica reúne obras de mais de 300 artistas cordobeses e reflete a multiplicidade de tendências, correntes e visões da arte local, através de linguagens como a pintura, o desenho, a gravura, a ilustração, a escultura, os objetos, a fotografia, a arte digital, a instalação e a performance ( $L a$ Voz del Interior. Quinta-feira, 27 de dezembro de 2007. Edição digital).

"Todos convidados" foi o título que o jornal usou para descrever a mostra de artistas cordobeses que expunham, ao mesmo tempo em que definia o tom da inauguração oficial com fogos de artifício e orquestra sinfônica.

\section{Todos Convidados}

A gestão responsável pela área de Cultura que está deixando o cargo convocou antes do dia 10 de dezembro 311 artistas cordobeses contemporâneos para participarem da primeira mostra do novo Museu Caraffa. Trata-se, sem dúvida, de uma exposição heterogênea que só pode ser dividida por grandes linhas de linguagem e tendências (mais ou menos convencionais), e que se propõe a ser "um relato provisório do universo visual que em sua mutação permanente desafia categorizações e catálogos excessivamente estabelecidos". Participam desde Carlos Alonso, Mario Rosso, Antonio Seguí, Dalmacio Rojas, Crist, Rafael 
Reyeros, Carlos Crespo, Bernardo Ponce, Norberto Cresta, Carlos Peiteado, Hernán Dompé e Remo Bianchedi, para citar apenas alguns dos nomes mais conhecidos, até autores de gerações intermediárias e muitos jovens com assinaturas de alto e baixo perfil ( $L a \mathrm{Voz}$ del Interior. Quinta-feira 27 de dezembro de 2007. Edição digital).

A inauguração, a primeira da gestão do resplandecente governador Juan Schiaretti, foi uma continuidade da obra de seu antecessor, José Manuel De la Sota, de quem havia sido vice-governador. A cerimônia apenas reafirmou a continuidade destas gestões governamentais.

Ainda que "todos" estivessem convidados, o convite não foi o mesmo para todos. Naquela noite houve dois circuitos de circulação claramente distintos e diferenciados, com um forte poder de distinção e diferenciação. Além do que a imprensa informou, houve outra performance dentro do Museu: o vernissage. Entre taças, champanhe, brilhos e câmeras de TV, encontravam-se reunidas autoridades políticas, artistas, mecenas, "gente da cultura", jornalistas e outras pessoas dentre as mais destacadas nos meios artísticos cordobeses. Elas haviam recebido um convite especial das autoridades do Museu, de algum dos expositores ou simplesmente foram porque se sentiram convidadas e sabiam que, apresentando-se de determinada maneira, com a ostentação adequada e os modos corporais indicados, as portas do museu se abririam automaticamente.

Estar fora do museu era literalmente não pertencer aos "mundos da arte" (Becker 1982) e à "Cultura" representada nesta performance. Estar dentro enquanto outros permaneciam fora e desfrutar risonhamente do álcool, da noite agradável, das instalações renovadas e das obras expostas era uma performance de Estado que interpelava esses sujeitos enquanto sujeitos da Cultura e os habilitava, desde que se reconhecessem como tais, à possibilidade de desfrutarem sensualmente do privilégio de sua posição. Especificamente, as pessoas se encontravam, conversavam, seduziam e se ignoravam, refazendo mais uma vez os vínculos que davam forma a esses mundos.

A performance no interior do Museu era a reedição de uma performance já realizada neste mesmo lugar alguns dias antes. A mostra de artistas cordobeses que o MEC exibia havia sido apresentada aos artistas em meio a um coquetel de despedida do governador que saía, que concluiu seu mandato sem ver concluídas as obras. Esta reunião não foi a inauguração oficial, pois ainda havia salas e espaços em acabamento, mas resultou em uma primeira exibição para os artistas do que seria o novo museu e de sua localização no mesmo. Neste sentido, poderia considerar-se o evento como um ensaio do que estava por vir. 
A consideração dos mecanismos a partir dos quais os artistas foram selecionados merece um parágrafo à parte. Na Sociedade da performance, da representação das relações sociais e do alto rendimento da personalidade, "ninguém quer ficar de fora". Como em uma grande comédia de enredos, o número de expositores crescia exponencialmente à medida que passavam os meses em que se organizava a mostra. A princípio, a direção do Museu havia selecionado um conjunto de artistas plásticos locais e convidou-os a enviar uma obra para ser integrada à exposição de "Arte Córdoba". À medida que os rumores circulantes nesses mundos davam a conhecer os nomes dos selecionados, crescia o mal-estar dos excluídos. Alguns, sem terem recebido convite, levavam suas obras como se tivessem sido convidados e tentavam impor seu nome com a força dos fatos.

Uma artista selecionada comentou comigo que quando foi entregar sua obra cruzou com uma colega que insistia ter recebido um telefonema pedindolhe para participar da mostra. O empregado que recebia as obras afirmava que ela não estava na lista, enquanto a artista repetia Não pode ser! Não pode ser! Como não vou estar?. Finalmente, deixou sua obra, ameaçando o empregado e dizendo-lhe que falaria pessoalmente com as autoridades do Museu. É uma falta de respeito aos artistas de Córdoba, dizem que repetia enquanto abandonava o local. Alguns, segundo pudemos averiguar, telefonaram e mandaram emails para ativar todo um capital social que colocasse em seu favor o convite. Outros também fizeram o impossível para não serem convidados, entendendo que não estar entre os expositores era parte de suas estratégias de distinção e consagração como artistas "contraculturais" ou independentes.

O grande número de convocados oficialmente para a inauguração, mais de 1.000 pessoas, os 300 expositores e a maciça presença do público em geral — milhares de pessoas segundo as crônicas da imprensa - pareciam confirmar performativamente a força de enunciados como "Todos convidados" ou "Cultura para todos". Tinha-se a impressão de que, agora sim, estávamos "todos", ainda que em termos demográficos fossem $0,2 \%$ da população da cidade de Córdoba, e dali se esperava uma gestão que continuaria abrindo o museu aos artistas cordobeses. O ano de 2007 chegava ao fim.

No início do ano seguinte, o diretor do $\mathrm{Museu}$, durante a gestão de De Sota, foi designado novamente para o cargo. ${ }^{17}$ Para um importante número de artistas locais, o Museu, apesar das promessas governamentais, parecia ter se tornado outra vez inacessível para a arte de Córdoba. Talvez, dando suporte a esta política de clausura, os vernissages tenham se tornado "fechados" durante a administração deste "diretor-artista".

Para entrar era preciso aparecer na lista de convidados e muitos dos que possuíam uma espécie de "passe livre" simbólico objetivado em seu 
nome deixaram de tê-lo e tiveram que ficar na porta das festas. Segundo o relato de uma entrevistada:

O assunto dos vernissages fechados foi um dos temas candentes daquele período. Te falo de 2008. O primeiro foi na exposição de Pablo Suárez. Um horror. Nós mesmos, que trabalhávamos no museu, não fomos à exposição em protesto, não porque não pudéssemos entrar. Só foi o enorme batalhão de guardas das salas que, naquele momento, a chefe de recursos humanos e administração havia criado.

Argumentava-se que esse formato atrairia patrocinadores privados. Os convidados eram pessoas vinculadas à Associação de Amigos [do Museu], empresários, políticos... e os trabalhadores do museu.

As bebidas e o serviço de catering eram abundantes nesses eventos que reuniam umas 200 pessoas e onde, uma vez mais, os funcionários teciam idealmente as relações entre "Cultura" e "Economia". Estar presente um um ambiente tão seleto era uma forma de incrementar a performance (rendimento) do próprio nome, na medida em que permitia aceitar, de um modo relaxado e hedonista, as relações de interdependência que ligavam os convidados.Tensos com as novas condições de trabalho, os empregados do Museu se negaram a participar do evento, buscando indicar com a sua ausência o clima irrespirável em que viviam.

Não poder participar desta performance (espetáculo) e passar a ser parte de um círculo elegante e secreto irritou muitos. Um vernissage para poucos era algo que não se podia tolerar. "O que estão pensando?... Até quando teremos que aguentar estas coisas? Temos que fazer algo!", declaravam enojados os vários excluídos da performance.

Rapidamente aquelas performances, que eram "públicas" e pareciam assegurar e realizar efetivamente o slogan "Cultura para todos", haviam se tornado fechadas. Era como se o "Estado" tivesse deixado de garantir a representação de si que tinham determinados agentes do campo cultural que, em outros momentos, desfrutaram do favor do convite. Ser convidado e fazer parte do vernissage que possibilitava ver a exposição antes do "público em geral" era um poderoso ato de reconhecimento.

Com a instauração de um regime de convites exclusivos e nominais, o verniz do vernissage já não cobria todos. Em consequência, o brilho que a performance emitia visibilizava a pobreza de capitais dos excluídos. Neste contexto, uma decisão aparentemente banal em termos de políticas culturais, como a ação de transformar os vernissages em um private view, ${ }^{18}$ sofreu vigorosa resistência e crítica, constituindo um dos pontos mais sensíveis da briga que levou ao afastamento do "diretor-artista". 
No início de 2009, um dono de galeria local foi designado como o novo diretor do MEC. Sua tarefa parecia ser a de abrir novamente o museu, reconfigurando os modos de gerir a instituição e reorganizar os recursos humanos que ela possuía. Uma das reformas mais notórias do "diretor-galerista" foi a de inaugurar simultaneamente todas as salas do Museu. Não apenas o museu seria "para todos", como também "todo" o museu estaria à disposição do público cordobês. O ex-diretor também era criticado por subutilizar o prédio e manter salas sem exposições por considerar que os artistas locais careciam de propostas afinadas com a instituição.

Essas megainaugurações começaram a ser acompanhadas por vernissages mais uma vez abertos "para todos", que atraíram um número crescente de pessoas. Segundo as estimativas oficiais, entre 800 e 1.000 pessoas participaram dessas performances de Estado. Esses eventos transformaram-se em ponto significativo de reunião dos que circulavam entre os mundos da arte e da cultura e em um momento de socialização e encontro lúdico com o Estado, destacado nas agendas culturais da cidade. Sua organização era parte importante das atividades de gestão que o "diretor-galerista" planejava, e que eram executadas por uma equipe de trabalho estimulada pela novidade da tarefa, pelas boas relações de trabalho e comprometida afetivamente com as atividades culturais. Para esses trabalhadores, o vernissage era, além disso, um motivo de preocupação e uma ocasião para o desfrute e o relaxamento depois do estresse provocado pela montagem e por todas as atividades relacionadas com a exposição.

A multidão, a noite estrelada, as bandas de rock tocando ao vivo, a distribuição gratuita de álcool, as luzes, os novos penteados estranhos de jovens vanguardistas, os perfumes caros, os vestidos de tecidos brilhantes, os trajes elegantes, as roupas na moda e de grifes internacionais fizeram desses eventos performances sociais que supostamente nada ficariam a dever às de Buenos Aires ou da Europa. Índices de uma contemporaneidade local, tais performances falavam da eficácia das políticas culturais governamentais que haviam conseguido finalmente "Cultura para todos".

A Revista cultural $\tilde{N}^{19}$ publicou uma importante nota em sua edição de 12 de junho de 2010, na qual relatava e dava força a esses sonhos e realidades cordobeses:

"É Berlim", antecipou-me com notável poder de síntese uma conhecedora (de arte, de museus, de inaugurações e de cidades europeias). Supus que exagerava. Minutos depois, estava em Berlim. Os cerca de 5.000 metros quadrados do Museu Emilio Caraffa - MEC, como prefere chamar-se agora, com ressonância contemporânea, três anos depois de sua ampliação e refuncionalização - 
são um rincão de Berlim em Córdoba, a cada noite das sete ao ano em que há uma inauguração e se recebem mais de mil pessoas, um número inusual para qualquer vernissage na Argentina. É que Alejandro Dávila, diretor do MEC, mudou a organização das inaugurações: em sete noites inauguram-se várias mostras simultâneas, que somam cerca de 40 ao ano. E cada uma dessas sete noites é uma festa cool com champanhe, sim, mas também com fernet com coca, para não esquecermos que isto é Córdoba. A reunião é nos jardins do museu, onde um grupo toca música de tango experimental, algo que soa à mistura de tango, punk, jazz e música eletrônica. Berlim. Está claro - espero - que se trata de uma brincadeira. De uma imagem, apenas, capaz de dar uma ideia aproximada do que falamos quando falamos do MEC, um museu de arte com padrões profissionais e de qualidade europeus, com espaços e critérios de exibição, segurança, conservação e curadoria mais frequentes no primeiro mundo do que na Argentina.

As mostras inauguradas há alguns dias foram diversas, correspondendo à ideia de que o MEC é um museu sem exclusões, onde há um lugar para todos na arte contemporânea (Revista N, n. 350, 12 de junho de 2010).

Oferecendo Arte, champanhe e fernet, ${ }^{20}$ sons experimentais, jardins e divertimento, o MEC construía uma cena inusual e capaz de fazer o público viajar, transportando-o para outra realidade, ainda que também capaz de fixá-lo a partir de certos bens, índices de uma identidade local, como fernet com coca, "para não esquecermos que isto é Córdoba".

Nesta "Berlim" de fantasia, "uma imagem, apenas", que se desvanecia como as bolhas do champanhe antes da chegada da meia-noite, as pessoas podiam exercitar uma versão distinta de si mesmas em que se reconheciam como aquilo que diziam ser. Essas "performances de Estado" criavam e faziam crer em uma "cultura", uma cool/tura, e com o direito de desfrutá-la. O "Estado", segundo diziam e faziam os vernissages do MEC, devia ocupar-se de satisfazer as "necessidades culturais" dos cidadãos, e fazê-lo de maneira eficiente, "com padrões profissionais e de qualidade europeus".

A sociedade exclusiva do private view organizada pela administração anterior do Museu se abriu com a nova gestão e, mais uma vez, o brilho que dava o verniz do vernissage ficou acessível para "todos".

As performances, enquanto práticas produtoras de subjetividades, encontram-se abertas a múltiplos usos e apropriações. Como sustenta Gerholm (1988), talvez existam umas poucas formas adequadas de realizar um ritual, mas não existe uma maneira única de experimentá-lo. Além de nos transportarem a Berlim, essas performances eram capazes de suscitar ironia e de cobrir com um manto de suspeita tudo o que ocorria ali. Com comentários do tipo "venho cobrar meus impostos", alguns expressavam e 
fundamentavam o direito de consumir mais álcool que arte. Com este gesto iconoclasta, essas pessoas dedicavam-se a desencantar a crença no caráter distinto e desinteressado da Arte e de seus vernissages, tanto quanto reafirmar seu pertencimento aos setores mais "contemporâneos" dos mundos da Arte. ${ }^{21}$ Outros comentários ressaltavam que ainda que se houvesse ampliado a base de participação, não havia ocorrido o mesmo com a verba, de modo que esses novos "vernissages populares" não estavam tão bem servidos e a bebida era escassa. Com um tom irônico, alguns convidados se animavam a pedir sarcasticamente o retorno do diretor anterior com o objetivo de marcar a atual ausência de um bom catering, à diferença de tempos passados.

No final de 2010, quando de um concurso público que recebeu críticas importantes, o "diretor-galerista" abandonou a direção com o apoio de grande parte desses mundos da arte que se encontravam nos vernissages que foram organizados durante sua gestão. Um funcionário e também artista plástico cordobês foi designado para o cargo e os vernissages continuaram, ainda que agora mais espaçados. O número de exposições anuais diminuiu, assim como a importância dos expositores convocados no campo artístico e a repercussão dos eventos na mídia. Esta nova situação (re)forçada pelo corte orçamentário fez com que também se perdesse um pouco o brilho que tinham os de antigamente. ${ }^{22}$

\section{Performatividade de Estado}

Em suas performances, o Estado parecia materializar-se duas vezes. De um lado, ele se produzia quando, com o objetivo de construir uma representação ou de montar uma performance, acrescentava e estatizava as relações de interdependência de diferentes agentes. A produção de vernissages ativava distintas redes de funcionários públicos que se reproduziam social e economicamente através da produção de (performance de) Estado. A organização da mostra e sua inauguração impulsionavam e reforçavam toda uma série de circuitos administrativos estatizados por onde circulavam expedientes e se mobilizava um número importante de agentes estatais do Museu e também da Secretaria de Cultura. A essas redes incorporavam-se pessoas tão diversas como fabricantes de sanduíches, garçons, donos de adegas, técnicos de som, desenhistas gráficos, eletricistas e críticos de arte que, contratados pelo Estado da Província de Córdoba, a ele se integravam. ${ }^{23}$

O "Estado" também se materializava como representação ou como imagem. A esta imagética estatal, como sustenta Tambiah (1985) em relação aos rituais e às cerimônias, estariam unidos e dela se infeririam determi- 
nados valores indiciais. Associados a uma cultura culta e às belas artes, os vernissages encarregavam-se de reforçar a distinção como recurso do Estado para produzir hegemonia.

Interpelados pelo Estado e convocados a tomar parte em suas performances, os convidados se faziam e se reconfirmavam em determinadas representações de si e em certas autoimagens ideais que lhes asseguravam uma posição dominante no campo cultural. O brilho que os vernissages desprendiam alimentava as fantasias dos participantes e seus desejos de pertencimento. Em um ambiente relaxado, algumas pessoas experimentavam e representavam uma cena que as colocava imaginariamente em uma dimensão global, "como em Berlim". Essas performances explorariam o desejo de reconhecimento que nos anima como pessoas (Butler 1997), ao mesmo tempo em que faziam do "Estado" um avalista privilegiado das representações e das identidades.

O trabalho conjunto de indivíduos do e com o "Estado" permitia montar um cenário concreto onde se jogavam, em uma espécie de "como se", os avatares da distinção cultural e da diferenciação social. Ainda que promovidos sob os ditames relacionados à universalização do acesso à Cultura, os vernissages habilitavam os jogos de distinção. Unidos e separados, os presentes no vernissage se dividiam entre: os convidados que assistiam voluntariamente e se autoidentificavam como "gente da cultura"; os trabalhadores vestidos de garçom para quem estar ali era uma obrigação; e os funcionários e artistas expositores que ocupavam uma situação intermediária.

Esta dinâmica se jogava, não o esqueçamos, sob o signo do lúdico e da experimentação de outros estados de consciência resultantes de certos consumos, como o de álcool e tabaco, mas também de marijuana, cocaína e psicofármacos que contribuíam para dotar essas performances de certo caráter subjuntivo. Mas, depois de tudo, Córdoba não era Berlim, e a distinção se desvanecia como num conto de fadas, antes da meia-noite. A satisfação obtida acabava sendo frustrada porque, como "todos" sabiam, depois do vernissage oficial, a festa continuava, mas já então apenas para "poucos", na casa de um colecionador ou de um funcionário.

Performances de Cultura como esses vernissages constituíam também uma cena privilegiada para a materialização do conflito. Melhor dizendo, os modos de participação das pessoas nesses eventos tornavam-se estratégias de visibilização pública na canalização de certas demandas ou reclamos sociais. A inauguração do MEC, por exemplo, deu lugar a contrafestejos e manifestações de alguns artistas na porta do Museu que não foram registrados pela imprensa e que não se mantiveram no tempo. Pelo contrário, algum tempo depois algumas dessas pessoas começaram a participar assiduamente dos 
vernissages e muitos dos que diziam desejar destruir pelas chamas o Museu Caraffa acabaram convertendo-se em curadores de exposições exibidas ali. ${ }^{24}$

Com toda a sua aparentemente frívola banalidade e seu encanto embriagador, os vernissages do MEC poderiam ser pensados como outros dispositivos através dos quais o "Estado", enquanto redes sociais estatizadas de intervenção cotidiana na vida social e enquanto imagem, materializava-se em um processo contraditório. A "magia do Estado" (Taussig 1997), consistente em seu poder de autoreproduzir-se e representar-se como um agente racional nos processos sociais, pode ser entendida como efeito performativo de, em parte, "performances de Estado", como esses vernissages. Através deles, algumas pessoas se divertiam jogando com o brilho e a magia estatal enquanto reproduziam seu capital econômico, social e político, e comiam, bebiam, seduziam, criticavam políticas governamentais, cultivavam uma experiência estética e faziam cultura. O Estado financiava a produção dessas cenas distintivas e para poucos sob o slogan de "Cultura para todos", mas o brilho que delas emanava e o interesse das pessoas pelas representações de si que o Estado lhes garantia tornavam (in)visível a instabilidade do enunciado. A partir de sua presença, mas também de sua ausência estratégica, essas pessoas faziam e se fazia "Estado" acreditando alegremente que durante algumas noites por ano "todos" eram esses poucos que participavam ativamente dos vernissages.

Recebido em 12 de outubro de 2011

Aprovado em 29 de março de 2012

Tradução de Maria Barroso Hoffmann

Gustavo Blázquez é pesquisador do Conicet e professor titular da Universidad Nacional de Córdoba. E-mail: <gustavoblazquez3@hotmail.com>

\section{Notas}

${ }^{1}$ Na França, durante os séculos XIV e XV, denominava-se representação à esfinge funerária do rei feita de couro, madeira ou cera utilizada nos rituais funerários (Cf. Blázquez 2000).

${ }^{2}$ Durante a última ditadura, a União Cívica Radical ocupou o Poder Executivo provincial até 1999, quando foi substituída pelo Partido Peronista, que até o presente 
é a força política hegemônica. José Manuel de la Sota foi governador da província de Córdoba em dois períodos consecutivos entre 1999 e 2007 e reeleito para ocupar o mesmo cargo em 2011. Juan Schiaritti foi vice-governador de Córdoba entre 2003 e 2007 e governador da mesma província entre 2007 e 2011. As práticas que este artigo analisa foram parte das ações de governo destes dois políticos peronistas. Durante seus governos modificaram-se, em mais de uma ocasião, as formas de organização dos corpos administrativos do Poder Executivo. Durante o período de 1999-2002, a Secretaria de Cultura transformou-se em Agência Córdoba Cultura Sociedade do Estado, uma forma organizativa dentro do marco jurídico nacional das sociedades civis e comerciais que distingue as Sociedades de Estado, que não permitem a participação de capitais privados, e as Sociedades Mistas, que os autorizam. Esta transformação foi parte de um processo maior de reorganização e modernização das formas de administração estatal. Em 2002, no contexto da crise econômica e institucional argentina de 2001, várias agências, algumas de Estado e outras Mistas, fundiram-se em uma grande Agência que administrava as áreas de Esporte, Cultura, Turismo e Meio Ambiente. Em 2004 esta megaorganização dissolveu-se e a Agência Córdoba Cultura recuperou sua autonomia. Em 2008, e já sob o governo de Schiaretti, voltou à sua antiga forma de Secretaria e, em 2012, novamente com de la Sota, voltou a seu estatuto de Agência de Estado. Estas transformações contínuas nas formas de organização e nos regimes jurídicos que as regulavam dificultam o conhecimento preciso do volume e das formas de execução do orçamento, assim como de outros dados que permitiriam uma análise exaustiva de seu funcionamento (Cf. Tamagnini 2010).

${ }^{3}$ Este slogan não pertence unicamente ao governo cordobês. Por exemplo, o Museu Oscar Niemeyer de Curitiba (Paraná) fazia a sua divulgação em 2011 com a frase "ARTE PARA TODOS. Visite o MON".

${ }^{4} \mathrm{Na}$ Assembleia estiveram presentes o presidente da Agência Córdoba Cultura, a diretora de Patrimônio Cultural e um funcionário da Agência Córdoba Turismo. O circuito jesuítico de Córdoba está integrado por cinco estâncias localizadas no interior da província: a Casa de Caroya (1616), as estâncias de Jesús Maria (1618), Santa Catalina (1622), Alta Gracia (1643) e La Candelaria (1683). A elas se soma o conjunto cêntrico da cidade de Córdoba, que compreende a Igreja da Companhia, a Capela Doméstica e dois prédios pertencentes à Universidade Nacional de Córdoba: o Colégio Nacional Monserrat e a Casa de Trejo.

${ }^{5}$ Esta Secretaria de Estado, criada em 2007 a partir da Agência Córdoba Cultura, tinha a seu cargo, entre outros, três teatros, cinco museus, 11 corpos artísticos, várias bibliotecas, o Arquivo Histórico Provincial e a Junta Provincial de História. Suas atividades estavam organizadas em diversas áreas, como: "Cinema, TV e vídeo", "Pensamento Latino-americano", "Cultura para o interior", "Gestão e Políticas Culturais", "Patrimônio e Museus" etc. (Cf. http://www.cba.gov.ar/canal.jsp?idCanal=27).

${ }^{6}$ Os prédios que abrigam estes três museus foram inaugurados em 2007, ano em que se realizaram eleições provinciais para governador e cargos legislativos. Todas as instituições que formavam este corredor cultural dependiam administrativamente da Secretaria de Cultura da Província de Córdoba. A Secretaria centraliza todos os gastos 
monetários, de tal modo que cada uma das instituições devia solicitar, por memorando, os fundos para financiar as atividades planejadas. O dinheiro proveniente da venda de entradas tampouco permanecia nas instituições, voltava à Secretaria. As distintas dependências não só careciam de autonomia na administração dos recursos, como também em muitas ocasiões não sabiam com certeza o orçamento anual concedido e só recebiam uma pequena soma mensal para gastos de funcionamento.

${ }^{7}$ Este espaço verde, vizinho ao Museu Caraffa, possui 201 círculos de cor que representam "fatos significativos" da história do país e da província desde 1810. O número 201 simboliza o futuro. A obra foi uma iniciativa conjunta do Governo Provincial de Córdoba, da Municipalidade da Cidade de Córdoba e do jornal La Voz del Interior. Uma escultura de um busto da rainha castelhana Isabel, a Católica (1451-1504), que se encontrava neste espaço antes da reforma, foi recolocada ali. O busto se conecta a partir de um fio d'água, que corre permanentemente, com o círculo 201, desenhando uma linha reta que liga a metrópole colonial europeia com o futuro de uma antiga ex-colônia.

${ }^{8} \mathrm{O}$ monumento ao General Juan Bautista Bustos, governador da província de Córdoba entre 1920 e 1929, foi inaugurado em 20 de maio de 2010 no trajeto que une o Museu Caraffa e a Cidade das Artes.

${ }^{9}$ Este monumento, uma torre de $102 \mathrm{~m}$ altura, está localizado a pequena distância do Museu Caraffa e foi inaugurado no dia 2 de junho de 2011. O Farol conta com um sistema de iluminação computadorizada e faz parte de um projeto mais amplo que está em construção, denominado "Centro de Interpretação do Bicentenário e Arquivo Histórico".

${ }^{10}$ As grandes obras públicas que facilitariam o acesso à Cultura faziam parte de renovações urbanas em determinadas áreas da cidade de Córdoba relacionadas à reativação do mercado imobiliário e à indústria de construção, por sua vez associados aos altos rendimentos do setor agrícola, especialmente do cultivo de soja. No início de 2011, os metros quadrados construídos na cidade de Córdoba superavam os de Buenos Aires, segundo informação do Mercado Imobiliário (Cf.http://www.cacic.com.ar/adjuntos/8. pdf). Ao mesmo tempo, o turismo internacional, fomentado pelos baixos preços a partir da desvalorização da moeda nacional em 2001, e o turismo nacional, facilitado pelo crescimento econômico dos últimos anos, nutriam-se e recriavam um valor patrimonial local fundado na singularidade do passado cordobês e em seu aporte à Humanidade.

${ }^{11}$ A Internacional Situacionista foi uma organização de intelectuais e artistas revolucionários formada em 1957 a partir da fusão de diferentes coletivos de artistas de vanguarda. O grupo se dissolveu em 1972 e sua participação é considerada central no maio de 1968 francês (Cf. Plant 2008).

${ }^{12}$ Para Debord, o espetáculo é uma visão do mundo objetivada que dá conta e realiza, mais uma vez, a alienação da produção capitalista garantida pelo Estado como órgão de dominação de classe que exerce o "monopólio das aparências". Na sociedade espetacular, "a cultura integralmente convertida em mercadoria deve coverter-se por sua vez em mercadoria estelar" (Debord 1999a:159). 
${ }^{13}$ Seguindo esta linha, programas televisivos com audiência massiva na Argentina, como "Cantando por um sonho" ou "Dançando por um sonho", propõem que a realização de um desejo (sonho), geralmente relacionada a alguma organização social ou benfeitora, seria conseguida mediante uma "boa" performance coreográfica e artística sujeita à avaliação por parte de um júri. Nos mundos da arte contemporânea, também observamos uma inflação de produções artísticas denominadas performances e a organização de festivais oficiais destinados a exibi-las.

${ }^{14}$ Estas questões estão presentes em alguns trabalhos que acompanhei como orientador. Laura Navallo analisa esses processos em sua tese de licenciatura em Antropologia, defendida na Universidade Nacional de Salta, através da análise da criação de uma Orquestra Sinfônica Provincial e da inauguração de um centro cultural e teatro chamado "Casa da Cultura". A partir da análise de documentos, entrevistas e observação participante, examina como essas ações estão envolvidas em uma transformação nos modos de representar a cidade (e a província) de Salta, que passou de "Salta, a linda" para "Salta é cultura", segundo os slogans utilizados por diferentes governos saltenhos para promover o turismo na região. Através do estudo dos sentidos associados ao termo cultura e de sua arqueologia nas práticas musicais locais, especialmente no folclore e na música culta, Navallo analisa as poéticas e políticas portadoras de uma missão civilizadora e educativa construídas em torno da "Cultura". A partir desta se (re)criam cidadãos e se constrói uma forma altamente legitimada de viver a saltinidade a partir de uma ação política cultural apoiada pelo governo provincial. Em sua perspectiva, estas ações, enquanto políticas culturais, "contribuem para incorporar certos atributos, socialmente construídos, como 'naturais' do 'saltenho'" (Navallo 2007:17). Estas questões foram retomadas pela autora em sua dissertação de mestrado (Navallo 2010). O trabalho de Lucía Tamagnini, “Performance e políticas culturais na inauguração do Museu Superior de Belas Artes Evita Palácio Ferreyra", analisa as políticas culturais do Executivo da província de Córdoba nos primeiros anos do século XXI para deter-se com especial atenção nas diferentes inaugurações do Museu Superior de Belas Artes Evita Palácio Ferreyra. Este museu, integrado à "Meia légua de ouro cultural", está localizado em uma luxuosa propriedade, o "Palácio Ferreyra", construída em 1916 e pertencente a uma família da alta burguesia local. A mansão de linhas francesas foi expropriada pelo Executivo provincial e remodelada para alojar a coleção de obras de arte (pinturas, esculturas, gravura e desenhos) patrimônio da Província de Córdoba. Segundo a discussão da autora a partir do uso de conceitos tomados da obra de Victor Turner, o palácio-museu resultou em um "símbolo dominante" (Turner 1967) em torno do qual se condensou uma multiplicidade de significados, muitas vezes contraditórios. Nas performances que se realizaram como parte da inauguração oficial, impunham-se e resistiam políticas culturais governamentais associadas à ideia de democratização cultural entendida como sinônimo de acesso, difusão e promoção da "cultura culta".

${ }^{15} \mathrm{O}$ termo, derivado do francês vernis ou verniz, designava no século XIX o tempo durante o qual, diante do público, os artistas davam os últimos retoques e aplicavam uma cobertura de verniz nas pinturas a óleo que seriam exibidas ao público a partir do dia seguinte. De gênero gramatical masculino em sua língua de origem, este substantivo pode ser utilizado como feminino. Neste trabalho o utilizamos em sua 
forma masculina por ser o modo reconhecido como legítimo por agentes altamente distinguidos no campo.

${ }^{16}$ Minhas atividades acadêmicas como diretor de Pós-Graduação em Administração e Gestão Cultural da Faculdade de Ciências Econômicas da Universidade Nacional de Córdoba, meu trabalho como crítico de Arte e as relações pessoais com distintos integrantes dos mundos da arte funcionavam como as principais credenciais a partir das quais eu era convidado. Por outro lado, em outubro de 2009, uma obra de minha autoria foi exibida no Museu como parte da instalação "Automatic Moving Company". Este pertencimento particular ao mundo da arte local a partir de minha posição de acadêmico, crítico, amigo e artista constituiu uma encruzilhada fundamental em virtude da qual se desenvolveu uma "participação observada" específica e se construiu esta peça de "conhecimento situado".

${ }^{17}$ Este funcionário participou ativamente do campo local das artes plásticas nos anos 80 e 90, sofrendo resistências por parte de seus colegas que o consideravam elitista e sectário.

${ }^{18}$ O private view também é um "coquetel de abertura" de uma mostra de arte que, à diferença do vernissage, está restrito apenas aos que possuem um convite.

${ }^{19}$ A Revista Ñ é uma revista dedicada a assuntos culturais, e é editada em Buenos Aires pelo Grupo Clarín, com uma periodicidade semanal desde 1996.

${ }^{20} \mathrm{O}$ fernet é uma bebida alcóolica de cor escura e sabor amargo feita a partir de ervas que devem ser bebidas misturadas com soda ou refrigerantes do tipo cola. Na província de Córdoba são consumidos $30 \%$ da produção nacional.

${ }^{21}$ Estas práticas encontravam-se em consonância, por exemplo, com as da Revista Ramona, destacada publicação sobre artes visuais publicada entre 2000 e 2010 , que anunciava em suas páginas: "A agenda de arte mais completa da Argentina. Beba grátis nos vernissages" (Cf. http://www.ramona.org.ar/files/r18.pdf). Segundo assinalado no jornal La Nación por ocasião de seu lançamento, "o gênero predominante neste primeiro número é a resenha de exposições. Os registros variam desde a crítica séria até a nota cheia de colorido sobre um vernissage. O humor, por outro lado, é uma constante que aflora em vários textos e, muito especialmente, nos títulos" (http://www.lanacion.com.ar/191825-ramona-salio-a-la-calle).

${ }^{22}$ Ainda que não tenhamos dados oficiais, sabemos que no ano de 2012 a dotação orçamentária para o MEC caiu 50\% em relação a 2011, ano em que ela já havia diminuído consideravelmente em relação a 2010.

${ }^{23}$ Escapa aos limites deste trabalho uma descrição mais acabada destas práticas, o que permitiria uma maior compreensão do processo de montagem material do Estado. Aproximar-se destas dinâmicas teria requerido abordagens metodológicas outras, que permitissem embrenharmo-nos pelos corredores e pelas vielas da administração pública. 
${ }^{24}$ Durante a inauguração do Museu "Evita", também se realizaram contrafestejos sob a forma de performances artísticas (Cf. Tamagnini 2010). Seria necessário fazer uma análise destas vozes discordantes e das disputas entre as diversas instituições culturais dependentes da Secretaria de Cultura e outras de caráter "independente". Este trabalho, demasiadamente extenso para ser incluído neste artigo, permitiria conhecer com maior precisão a arena de disputas políticas locais da qual faziam parte as performances aqui analisadas.

\section{Referências bibliográficas}

ANGERER, Marie. 2009. "Performance y performatividad". In: H. Butin (org.), Diccionario de conceptos de arte contemporáneo. Madrid: Abada. pp. 178-181.

BECKER, Howard.1982. Art worlds. Berkeley: University of California Press.

BENJAMIN, Walter. 1989. Discursos interrumpidos I. Madrid: Taurus.

BLÁZQUEZ, Gustavo. 1998. Escola de patriotismo. A construção da Argentina e dos argentinos através das performances patrióticas escolares. Dissertação de mestrado, PPGAS/MN/UFRJ

- 2000. "Exercícios de apresentação: antropologia social, rituais e representações". In: C. F. Cardoso \& J. Malerba (orgs.), Representações. Contribuição a um debate transdisciplinar. Campinas: Papirus. pp. 169-198.

BOURDIEU, Pierre. 1994. Raisons pratiques. Sur la théorie de l'action. Paris: Éditions du Seuil.

BUTLER, Judith. 1997. The psychic life of power. Stanford: Stanford University Press.

CASTRO, João Paulo Macedo. 2009. A invenção da juventude violenta. Análise da elaboração de uma política públi$c a$. Rio de Janeiro: E-papers/LACED, Museu Nacional.

CORRÊA, José Gabriel Silveira. 2002. A ordem a se preservar: a gestão dos índios e o Reformatório Agrícola Indígena Krenak. Tese de doutorado, PPGAS/Museu Nacional/UFRJ.

DEBORD, Guy. 1999a. La sociedad del espectáculo. Valencia: Pre-Textos. . 1999b. Comentarios sobre la sociedad del espectáculo. Barcelona: Anagrama.

ELIAS, Norbert. 1987. El proceso de la civilización. Investigaciones sociogenéticas y psicogenéticas. Buenos Aires: FCE.

-1997. Os alemães: a luta pelo poder e a evolução do habitus nos séculos XIX e XX. Rio de Janeiro: Jorge Zahar Editor

FOUCAULT, Michel. 1975. Surveiller et punir. Paris: Gallimard.

GEERTZ, Cliford. 1981. Negara: the theatre State in $19^{\text {th }}$ century Bali. Princeton: Princeton University Press.

GERHOLM, Thomas, 1988. "On ritual: a posmodernist view". Ethnos, LIII(3-4): 190-203.

GLUCKMAN, Max. 1958. Analysis of a social situation in modern Zululand. Manchester: Manchester University Press.

GOMBRICH, Ernest. 2004. Breve historia de la cultura. Madrid: Peninsula.

HOBSBAWN, Eric \& RANGER, Terence (orgs). 1984. A invenção das tradições. Rio de Janeiro: Paz e Terra. 
KUPER, Adam. 2001. Cultura. La versión de los antropólogos. Barcelona: Paidós.

LEBOVICS, Herman. 2000. La misión de Malraux. Salvar la cultura francesa de las fábricas de sueños. Buenos Aires: Eudeba.

LENOIR, Remy. 1993. "Objeto sociológico y problema social". In: P. Champagne et al. (orgs.), Iniciación a la práctica sociológica. México: Siglo XXI. pp. 57-102.

LUGONES, María Gabriela. 2009. "Obrando en autos, obrando en vidas". Formas e fórmulas de proteção judicial dos Tribunais Prevencionais de Menores de Córdoba, Argentina, nos começos do século XXI. Tese de doutorado em Antropologia, PPGAS/MN/UFRJ, Rio de Janeiro.

NAVALLO, Laura. 2007. Tocando cultura. Políticas y poéticas del término cultura a partir del análisis de los procesos sociales de creación de la Orquesta Sinfónica de Salta. Tesis de Licenciatura en Antropología, Universidad Nacional de Salta.

- 2010. Fazer cultura. Arte e política cultural em Salta, Argentina. Dissertação de Mestrado, PPGAS/MN/UFRJ.

PACHECO DE OLIVEIRA, João. 1988. O nosso governo: os Ticuna e o regime tutelar. São Paulo/Brasilia: Marco Zero/CNPq.

PHELAN, Peggy. 1993. Unmarked. The politics of performance. Londres: Routledge. PLANT, Sadie. 2008. El gesto más radical. La Internacional Situacionista en una época posmoderna. Madrid: Errata naturae.

RADCLIFE BROWN, Alfred. 1970. "Preface". In: M. Fortes \& E. Evans Pritchard (orgs.), African political systems. Oxford: Oxford University Press. pp. XI-XXIII. RAMOS, Jair de Souza. 2002. O poder de domar do fraco: formação de Estado e poder tutelar na Política de Povoamento do Solo Nacional. Tese de doutorado, PPGAS/MN/Museu Nacional.
RIFKIN, Jeremy. 2000. La era del acceso. La revolución de la nueva economía. Barcelona: Paidós.

SCHECHNER, Richard. 2000. Performance. Teoría y prácticas interculturales. Buenos Aires: Libros del Rojas - UBA. SOUZA LIMA, Antonio Carlos de. 1995. Um grande cerco de paz. Petrópolis: Vozes.

_. (org). 2002. Gestar e gerir. Estudos para uma antropologia da administração pública no Brasil. Rio de Janeiro: Relume-Dumará.

- \& CASTRO, João Paulo Macedo. 2008. Política(s) Pública(s). Mimeo.

TAMAGNINI, María Lucía. 2010. Performance y políticas culturales en la inauguración del Museo Superior de Bellas Artes "Evita- Palacio Ferreyra". Tesis de Licenciatura en Historia, Universidad Nacional de Córdoba.

TAMBIAH, Stanley. 1985. Culture, thought and social action. Cambridge: Harvard University Press.

TAUSSIG, Michael. 1992. The nervous system. New York: Routledge. . 1997. The magic of the State. New York: Routledge. - 1999. Defacement. Public secrecy and the labor of the negative. Stanford: Stanford University Press.

TURNER, Victor. 1967. The forest of symbols. Aspects of ndembu ritual. Londres: Cornell University Press. . 1986. The anthropology of perfomance. New York: PAJ.

VIANNA, Adriana. 2002. Os limites da minoridade: responsabilidade, tutela e família em julgamento. Tese de doutorado, PPGAS/MN/UFRJ.

YúDICE, George. 2002. El recurso de la cultura. Barcelona: Gedisa.

ŽIŽEK, Slavoj. 2003. A propósito de Lenin. Política y subjetividad en el capitalismo tardío. Buenos Aires: Editorial Atuel. 


\section{Resumo}

O artigo explora os processos de formação do Estado e as políticas culturais governamentais em Córdoba (Argentina) durante a primeira década do século XXI. A partir da análise das cerimônias que marcam a inauguração de mostras de arte, ou vernissages, são discutidas as dimensões performativas das práticas estatais e descritas performances que, em nome da cultura, "fazem Estado" através de formas altamente estetizadas que apelam para a captação sensorial. Nessas performances, que envolvem os sujeitos a partir da estimulação poética de seus sentidos, o Estado se materializa duas vezes. A "magia do Estado" se faz quando acrescenta e estatiza as relações de interdependência entre diferentes agentes e quando materializa uma imagem atraente encarregada de reforçar a distinção como recurso para a produção de hegemonia.

Palavras-chave Performance, Performatividade, Estética, Estado, Políticas culturais.

\section{Abstract}

The present article explores processes of State formation and government cultural policies in Córdoba (Argentina) during the first half of the 21st century. Analyzing the cerimonies that attend the inauguration of art exhibits - vernissages we discuss the performative dimensions of State practices that, in the name of culture, "make the State" through highly esteticized forms which appeal to the senses. In these performances, the State is materialized in two ways. The "magic of the State" occurs when interdependent relationships between agents appears and is institutionalized and also when na attractive image materializes that destined to reinforce this distinction as a resource for the production of hegemony.

Key words Performance, Performativity, Esthetics, State, Cultural policy. 